\title{
Cognitive reserve, presynaptic proteins and dementia in the elderly
}

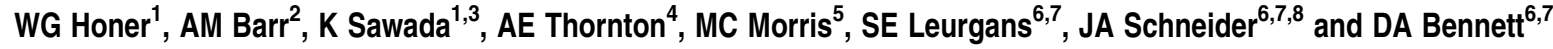

Differences in cognitive reserve may contribute to the wide range of likelihood of dementia in people with similar amounts of age-related neuropathology. The amounts and interactions of presynaptic proteins could be molecular components of cognitive reserve, contributing resistance to the expression of pathology as cognitive impairment. We carried out a prospective study with yearly assessments of $N=\mathbf{2 5 3}$ participants without dementia at study entry. Six distinct presynaptic proteins, and the proteinprotein interaction between synaptosomal-associated protein 25 (SNAP-25) and syntaxin, were measured in post-mortem brains. We assessed the contributions of Alzheimer's disease (AD) pathology, cerebral infarcts and presynaptic proteins to odds of dementia, level of cognitive function and cortical atrophy. Clinical dementia was present in $N=97(38.3 \%)$, a pathologic diagnosis of $A D$ in $N=142(56.1 \%)$ and cerebral infarcts in $N=77(30.4 \%)$. After accounting for $A D$ pathology and infarcts, greater amounts of vesicle-associated membrane protein, complexins I and II and the SNAP-25/syntaxin interaction were associated with lower odds of dementia (odds ratio $=0.36-0.68, P<0.001$ to $P=0.03)$ and better cognitive function $(P<0.001$ to $P=0.03)$. Greater cortical atrophy, a putative dementia biomarker, was not associated with AD pathology, but was associated with lower complexin-II $(P=0.01)$ and lower SNAP-25/syntaxin interaction $(P<0.001)$. In conclusion, greater amounts of specific presynaptic proteins and distinct protein-protein interactions may be structural or functional components of cognitive reserve that reduce the risk of dementia with aging.

Translational Psychiatry (2012) 2, e114; doi:10.1038/tp.2012.38; published online 15 May 2012

\section{Introduction}

Individual differences in cognitive reserve may explain the wide variation in the likelihood of dementia, and severity of cognitive impairment in people with comparable levels of neuropathology. ${ }^{1}$ Cognitive reserve could be associated with the level of education and other life experiences; however, the neural correlates are unclear. Synaptic terminals might contribute, as these subcellular complexes are vital for cognitive function in health and disease. ${ }^{2}$ Presynaptic terminals are enriched for multiple proteins, each providing specialized contributions to neurotransmission, and to cognitive functioning. ${ }^{3-8}$ Dynamic changes in synaptic terminal number, protein composition and function contribute to cognitive development during brain growth and maturation. ${ }^{9}$

As the brain ages, amyloid plaques and neurofibrillary tangles commonly accumulate, and infarcts may occur. Both pathologies contribute to the odds of dementia and the severity of cognitive impairment in an additive manner. ${ }^{10-12}$ In end-stage Alzheimer's disease (AD), presynaptic terminals are lost. ${ }^{13}$ The magnitude of loss of molecules such as the synaptic vesicle protein synaptophysin correlates with antemortem cognitive dysfunction. ${ }^{13}$ However, pan-synaptic terminal loss does not occur in less severe cases, ${ }^{14-16}$ and synaptic terminal integrity could contribute to delayed progression of cognitive impairment. Animal models of $A D$ suggest that synaptic dysfunction may occur early, before loss of terminals in later stages of illness. ${ }^{17,18}$

Direct, in vivo markers for synaptic pathology are not yet available, although changes in glucose utilization identified with positron emission tomography could reflect synaptic dysfunction. ${ }^{19-21}$ In the present study, we assayed multiple presynaptic proteins and a functionally important, presynaptic protein-protein interaction ${ }^{22}$ across cortical regions susceptible to $A D$ pathology. Our purpose was to relate these presynaptic markers to clinical dementia and severity of cognitive impairment after accounting for the two most common pathologic causes of age-related dementia. We also explored the relationships of $A D$ pathology and the presynaptic proteins to post-mortem assessments of cortical atrophy, ${ }^{23}$ as an analog of in vivo magnetic resonance imaging. The data were obtained from the Memory and Aging Project (MAP), a community-based study. ${ }^{24}$ The prospective design maximizes the relevance of the findings to the broad population of the elderly, with the full range of cognitive health and impairment.

\footnotetext{
${ }^{1}$ Department of Psychiatry, University of British Columbia, Vancouver, BC, Canada; ${ }^{2}$ Department of Anesthesia, Pharmacology and Therapeutics, University of British Columbia, Vancouver, BC, Canada; ${ }^{3}$ Department of Neuropsychiatry, Kochi University, Kochi, Japan; ${ }^{4}$ Department of Psychology, Simon Fraser University, Burnaby, BC, Canada; ${ }^{5}$ Department of Internal Medicine, Rush University Medical Center, Chicago, IL, USA; ${ }^{6}$ Rush Alzheimer's Disease Center, Rush University Medical Center, Chicago, IL, USA; ${ }^{7}$ Department of Neurological Sciences, Rush University Medical Center, Chicago, IL, USA and ${ }^{8}$ Department of Pathology, Rush University Medical Center, Chicago, IL, USA

Correspondence: Dr WG Honer, Department of Psychiatry, University of British Columbia, 2255 Wesbrook Mall, Vancouver, BC, Canada, V6T 2 A1.
}

E-mail: william.honer@ubc.ca or honer@ interchange.ubc.ca

Keywords: Alzheimer's disease; cognitive reserve; complexin; dementia; SNARE protein

Received 12 January 2012; revised 26 March 2012; accepted 5 April 2012 


\section{Materials and methods}

Population selection and cognitive evaluation. Elderly participants in MAP were free of known dementia at enrollment. ${ }^{24}$ Each participant signed an informed consent and an anatomic gift act. The study was approved by the institutional review board of Rush University Medical Center. From November 1997 through June 2010, > 1400 individuals completed the baseline evaluation.

The annual structured evaluation included a medical history, neurologic examination and testing of cognitive abilities commonly affected by aging and $A D$ in order to derive a global cognitive score. ${ }^{25}$ Test results were reviewed by a board-certified neuropsychologist. Experienced clinicians diagnosed dementia and $A D$ according to the criteria of the National Institute of Neurologic and Communicative Disorders and Stroke and the Alzheimer Disease and Related Disorders Association. Cognitive impairment not meeting the criteria for dementia was diagnosed as mild cognitive impairment. Identical follow-up evaluations were performed annually, blinded to previously collected data, with the overall follow-up rate of survivors in excess of $90 \%$.

Through June 2010, > 350 participants died and underwent brain autopsy, with a rate in excess of $80 \%$. Of these, the first consecutive 253 were included in the study of presynaptic terminals. In the examination nearest to death, $83(32.8 \%)$ of participants had no cognitive impairment, 73 (28.9\%) had mild cognitive impairment and 97 (38.3\%) had dementia.

Neuropathological assessment. A board-certified neuropathologist made pathologic diagnoses blinded to age and clinical data. The pathologic diagnosis of $A D$ was made following examination of modified Bielschowsky silver-stained $6 \mu \mathrm{m}$ paraffin-embedded sections to visualize neuritic plaques and neuronal neurofibrillary tangles in the cortex (midfrontal, middle temporal, inferior parietal, entorhinal and hippocampus CA1 sector). The diagnoses used National Institute on Aging (NIA)-Reagan criteria, which incorporates Consortium to Establish a Registry for Alzheimer's Disease (CERAD), with a Braak score (based on the distribution and severity of neurofibrillary tangles). ${ }^{26}$ Cases with either an intermediate or high likelihood of $A D$ by Reagan criteria were considered to fulfill criteria for the pathologic diagnosis of AD. Macroscopic infarcts were determined by the evaluation of $1 \mathrm{~cm}$ coronal slabs of both cerebral and cerebellar hemispheres and on cross-section of the brainstem at the pons. After histological confirmation, old, macroscopic cerebral infarcts were summarized as present or absent. ${ }^{27}$ A global AD pathology score was determined by counting neuritic plaques, diffuse plaques and neurofibrillary tangles in a $1 \mathrm{~mm}^{2}$ area of greatest density in each of the five cortical regions. A standard distribution was calculated for each regional count for each type of pathology across all people, and then summary scores were calculated across regions, and finally a single global $A D$ pathology score was calculated as the mean score of the 15 measures. ${ }^{28}$ Apolipoprotein $E(A P O E)$ genotyping was performed with PCR assays by Agencourt (Beckman Coulter Genomics, Brea, CA, USA).
Presynaptic protein analysis. Monoclonal antibodies were used to quantify immunoreactivity for six presynaptic proteins (see Supplementary Table S1). ${ }^{22}$ Frozen samples of gray matter were obtained from seven cortical regions susceptible to $A D$ and contralateral to those used for histology: entorhinal cortex proper (Brodmann area 28), hippocampus (including CA1/subiculum), superior frontal cortex (BA6/8), dorsolateral prefrontal cortex (BA46/9), inferior temporal cortex (BA20), angular gyrus cortex (BA39) and anterior cingulate cortex (BA24). Each sample was prepared for an enzyme-linked immunosorbent assay (ELISA) in serial dilution steps. ${ }^{16}$ The protein concentration required to obtain the same fixed optical density value across all samples was determined from dilution curve fitting. This value of total homogenate protein concentration was inversely related to the amount of target antigen present. Values were log transformed, the mean for each participant across the seven brain regions was determined and a standardized score across all participants was calculated for each synaptic protein. This approach to provide an overall indicator of presynaptic protein integrity with minimal measurement error is similar to the approaches used to quantify global pathology and global cognitive function. ${ }^{28}$ The standardized scores were multiplied by negative 1 to make the results intuitively easier to understand as being directly, rather than inversely, related to the amount of target antigen.

Protein-protein interactions between synaptosomalassociated protein 25 (SNAP-25) and syntaxin were assessed using a high-throughput immunoprecipitation strategy implemented with a heterologous capture ELISA. ${ }^{22}$ Purified antibody directed against one of the targets (SNAP-25 or syntaxin) was immobilized on an ELISA plate, serially diluted brain homogenate samples were incubated on the plate, and then a second antibody was added to detect the proteinbinding partner (syntaxin or SNAP-25) of the initially captured target (SNAP-25 or syntaxin respectively). The SNAP-25/ syntaxin and syntaxin/SNAP-25 interactions were highly correlated $(r=0.77 ; P<0.001)$ and a single mean value was calculated for each sample.

Approximately 10 brains (70 samples, 6 antibodies and 2 protein-protein interaction assays) were included in each assay run. Studies of the $n=253$ brains were carried out over 6 years. The following quality control procedures were used. Primary antibodies were produced in-house. Tissue culture supernatants were subject to titer tests to ensure that detection antibodies were consistent in potency. Antibodies that were purified for the protein-protein interaction studies were used at an optimized, fixed protein concentration. ${ }^{22}$ All sample assays were performed with duplicate serial dilution curves on each plate, and responses were assessed for linearity. Within-run variability was assessed by using a reference sample on each plate. The within-run coefficient of variation for the reference sample (at least three measurements) was required to be $<10 \%$, and routinely values of $<5 \%$ were obtained. Each assay run was repeated on a separate day, and the mean result for each sample was used. Run-to-run correlations required to exceed $r=0.8$, and correlations were routinely $r>0.95$. Using a consistent reference sample on every run allowed adjustment of absolute values of assay results between runs. We also used the 
reference assay results to examine the possibility of decline in immunoreactivity over time related to sample storage duration, and did not observe this effect. We were fortunate to have the same technical staff performing assays over the duration of the study.

To characterize the subcellular overlap between the interacting SNARE proteins and excitatory (glutamateric) and inhibitory (GABAergic) terminals, we used triple immunolabeling and confocal microscopy. ${ }^{22}$ Hippocampal tissue from two cases was fixed in $4 \%$ paraformaldehyde for at least $72 \mathrm{~h}$; sections were cut $10 \mu \mathrm{m}$ thick. Immunostaining used mouse monoclonal antibodies reactive with SNAP-25, syntaxin and vesicle-associated membrane protein (VAMP; Supplementary Table S1), and rabbit polyclonal antibodies reactive with the vesicular glutamate- 1 and vesicular GABA transporters (Synaptic Systems, Göttingen, Germany). Detection used subclass- and species-specific secondary antibodies labeled with Alexa-488, -555 or -647 (Molecular Probes, Life Technologies, Grand Island, NY, USA) and a confocal microscope (LSM-5 Pascal, Zeiss, Toronto, ON, Canada). Fields of view were focused on the dentate granule cell layer, and the extent of overlapping immunostained pixels was determined.

Statistical analysis. We examined subsets of cases with definite $A D$ (probable AD clinically, and high likelihood AD by NIA-Reagan, no gross infarctions or other pathology, $N=20$ ), and with no dementia and no or minimal pathology (no or low likelihood AD by NIA-Reagan, $N=18$ ). Correlations between global cognitive function and synaptophysin level were examined, and the difference in synaptophysin level between cases and controls was assessed with analysis of variance controlled for age, sex and education to confirm the well-documented finding of low synaptophysin in brains from people with moderate-tosevere dementia relative to normal brains.

For the full sample, all analyses used age, sex and education as covariates. We first used linear regression to examine the relationships between presynaptic proteins and global cognitive function. Subsequent analyses were restricted to the four measures with statistically significant effects. We used multiple logistic regression models to examine the associations of global AD pathology, cerebral infarcts and the presynaptic measures with the odds of dementia. A parallel set of analyses used multiple linear regression to investigate the relation of global $A D$ pathology, infarcts and presynaptic measures to global cognitive function.

Nonparametric tests of correlation between cortical atrophy and presynaptic measures utilized Spearman's rank correlation. Ordinal logistic regression analysis was carried out to examine presynaptic proteins as predictors for cortical atrophy, controlled for age, education and sex. Effect sizes for measures of correlation, and within models for change in variance, were defined respectively as small $(0.10,0.01)$, medium $(0.30,0.06)$ or large $(\geqslant 0.50,0.14){ }^{29,30}$

\section{Results}

Sample characteristics. Descriptive statistics for demographic cognitive and pathological variables appear in Table 1. As observed in other studies, there were no statistically significant correlations between levels of the presynaptic proteins or the SNAP-25/syntaxin interaction, and age, education or post-mortem interval. ${ }^{16,22,31}$ There were no differences in presynaptic proteins or the SNAP-25/syntaxin interaction between smokers and nonsmokers, and no statistically significant correlations between the presynaptic measures and amount of alcohol consumption per day in the year before baseline $(n=248)$. A history of breathing problems in the 3 days before death, or unconsciousness in the hour before death, did not influence the presynaptic measures ( $n=126$ with available information).

Synaptophysin in definite AD versus controls. In this analysis, global cognitive function was correlated with the level of synaptophysin $(r=0.46, \quad N=38, \quad P=0.004)$, representing a medium-to-large effect size. The mean level of synaptophysin was $29.5 \%$ lower in these AD cases compared with nondemented controls with no or minimal pathology (95\% confidence interval $=3.2-48.8 \%, P=0.03$ ). This confirms a well-documented association.

Presynaptic proteins and dementia. Screening analyses of the presynaptic protein relationships with global cognitive function in the full sample showed that VAMP, complexin-I, complexin-II and the SNAP-25/syntaxin interaction were

Table 1 Demographic, cognitive and pathological variables

\begin{tabular}{|c|c|}
\hline & $\begin{array}{l}\text { Proximate to } \\
\text { death, } \mathrm{N}=253\end{array}$ \\
\hline \multicolumn{2}{|l|}{ Demographic } \\
\hline Age, years & $88.2 \pm 6.0^{\mathrm{a}}$ \\
\hline Female sex, no. (\%) & $155(61.3 \%)$ \\
\hline Race white, non-Hispanic, no. (\%) & $242(95.7 \%)$ \\
\hline Education, years & $14.5 \pm 2.9$ \\
\hline APOE e4 allele, no. (\%) & $63(26.1 \%)$ \\
\hline \multicolumn{2}{|l|}{ Cognitive function } \\
\hline Global cognition score ${ }^{b}$ & $-0.76 \pm 1.10^{c}$ \\
\hline MMSE $^{d}$ & $21.9 \pm 8.8^{\mathrm{e}}$ \\
\hline Clinical dementia present & $97(38.3 \%)$ \\
\hline \multicolumn{2}{|l|}{ Pathological } \\
\hline Post-mortem interval, $\mathrm{h}$ & $7.0 \pm 4.5^{\mathrm{a}}$ \\
\hline AD pathological diagnosis, no. (\%) & $142(56.1 \%)$ \\
\hline NIA high, no. (\%) & $37(14.6 \%)$ \\
\hline NIA intermediate, no. (\%) & $105(41.5 \%)$ \\
\hline Infarcts, no. (\%) & $77(30.4 \%)$ \\
\hline AD pathology score ${ }^{f}$ & $0.68 \pm 0.63$ \\
\hline \multicolumn{2}{|l|}{ Cortical atrophy score ${ }^{g}$} \\
\hline Mild, no. (\%) & $36(14.2 \%)$ \\
\hline Mild to moderate, no. (\%) & $36(14.2 \%)$ \\
\hline Moderate, no. (\%) & $94(37.2 \%)$ \\
\hline Moderate to severe, no. (\%) & $63(24.9 \%)$ \\
\hline Severe, no. (\%) & $24(9.5 \%)$ \\
\hline
\end{tabular}

Abbreviations: AD, Alzheimer's disease; APOE, apolipoprotein E; MMSE, MiniMental State Examination; NIA, National Institute on Aging.

Mean and s.d. unless noted otherwise. ${ }^{\text {aT }}$ The data were obtained from 252 participants. ${ }^{\mathrm{b}}$ The global cognition score is a standardized score derived from the results of 19 tests of cognitive abilities commonly affected by aging and AD. ${ }^{25}$ Lower scores represent poorer cognitive function. ${ }^{\mathrm{C}}$ The data were obtained from 250 participants. ${ }^{\mathrm{d}}$ MMSE scores range from 0 to 30 , with lower scores indicating poorer cognitive function. ${ }^{\mathrm{e}}$ The data were obtained from 251 participants. 'Standardized scores of diffuse and neuritic plaques and neurofibrillary tangles were used to obtain a global measure of $A D$ pathology for each subject (see text). ${ }^{9}$ Cortical atrophy was rated independent of age by a neuropathologist on a 7-point scale from none (0) to severe (6). 


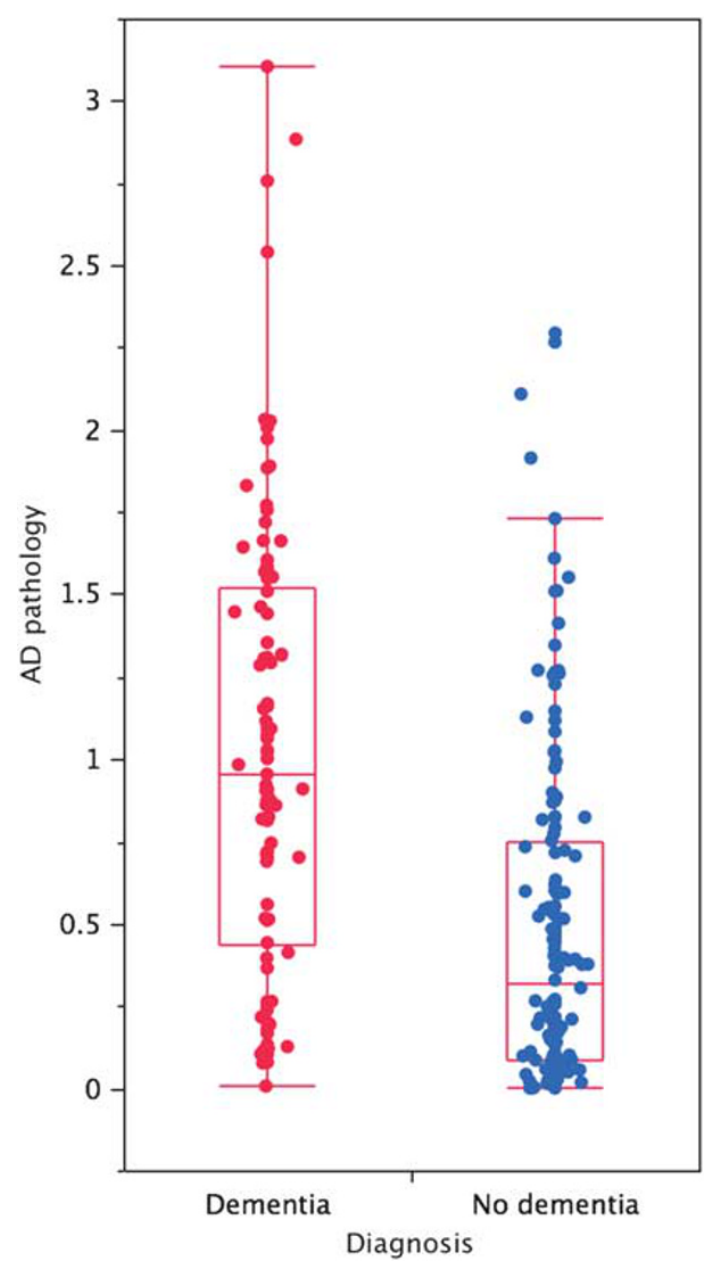

Figure 1 Variability and overlap in Alzheimer's disease (AD) pathology within and between dementia and no-dementia subgroups. The ends of the boxes depict the 25th and 75th percentiles in each group, and the line across the middle is the median. The whiskers represent 1.5 times the interquartile range. associated with cognitive functioning (Supplementary Table S2). In the total sample, synaptophysin, SNAP-25 and syntaxin levels failed to show such an association.

In both demented and nondemented participants, there was considerable variation within each of these groups in the severity of $A D$ pathology (Figure 1). Each unit of $A D$ pathology, and the presence of infarcts, increased the odds of dementia (Table 2). In contrast, each unit of VAMP, complexin-I, complexin-II and the SNAP-25/syntaxin interaction reduced the odds of dementia. The magnitude of reduction in the odds of dementia related to each unit of presynaptic protein (protective effect) was comparable to or larger than the increase in odds related to cerebral infarcts (damaging effect). This suggests that the level of specific presynaptic proteins and protein-protein interactions is highly clinically relevant. Figure 2 illustrates the effects of percentile of presynaptic proteins on odds of dementia across the spectrum of $A D$ pathology for a representative participant (an 88-year-old woman with 14 years of education). Statistical interactions between AD pathology and presynaptic markers were not significant, supporting a model of additive effects of pathology and presynaptic proteins on odds of dementia.

Presynaptic proteins and global cognitive function. Greater AD pathology and infarcts were each associated with poorer global cognitive function (Table 3). Age, sex, education and the pathological measures together explained $28 \%$ of the variance in global cognitive function, leaving considerable remaining variance. Adding the presynaptic proteins to the model demonstrated significant effects for each of the four indices, and contributed 1 to $9 \%$ additional variance (small-to-medium effect sizes). Figure 3 uses data from all study samples to illustrate the additive effects of unit amounts of AD pathology, and unit amounts of VAMP, complexin-I, complexin-II and the SNAP-25/syntaxin interaction on cognitive function. Across the range of $A D$

Table 2 Logistic regression model of the estimated odds ratios of clinical dementia per unit of AD pathology, cerebral infarcts and per unit of presynaptic measures for $N=249$ deceased MAP participants ${ }^{a}$

\begin{tabular}{|c|c|c|c|c|c|c|}
\hline Terms & Odds ratio & (95\% CI) & P-value & Odds ratio & $(95 \%$ CI) & P-value \\
\hline $\begin{array}{l}\text { AD pathology score } \\
\text { Cerebral infarcts }^{\mathrm{b}} \\
\text { VAMP }^{\mathrm{d}}\end{array}$ & $\begin{array}{l}4.81 \\
2.01\end{array}$ & $\begin{array}{l}(2.82-8.22) \\
(1.04-3.88)\end{array}$ & $\begin{array}{c}<0.001 \\
0.02\end{array}$ & $\begin{array}{l}4.58 \\
1.92 \\
0.68\end{array}$ & $\begin{array}{l}(2.67-7.88) \\
(0.99-3.72) \\
(0.44-1.03)\end{array}$ & $\begin{array}{c}<0.001 \\
0.02 \\
0.03\end{array}$ \\
\hline $\begin{array}{l}\text { AD pathology score } \\
\text { Cerebral infarcts } \\
\text { Complexin-I }^{\mathrm{e}}\end{array}$ & $\begin{array}{l}4.81 \\
2.01\end{array}$ & $\begin{array}{l}(2.82-8.22) \\
(1.04-3.88)\end{array}$ & $\begin{array}{c}<0.001 \\
0.02\end{array}$ & $\begin{array}{l}5.15 \\
2.36 \\
0.36\end{array}$ & $\begin{array}{l}(2.87-9.25) \\
(1.17-4.80) \\
(0.22-0.58)\end{array}$ & $\begin{array}{r}<0.001 \\
0.008 \\
<0.001\end{array}$ \\
\hline $\begin{array}{l}\text { AD pathology score } \\
\text { Cerebral infarcts } \\
{\text { Complexin- } I^{\dagger}}^{\dagger}\end{array}$ & $\begin{array}{l}4.81 \\
2.01\end{array}$ & $\begin{array}{l}(2.82-8.22) \\
(1.04-3.88)\end{array}$ & $\begin{array}{c}<0.001 \\
0.02\end{array}$ & $\begin{array}{l}4.66 \\
2.32 \\
0.52\end{array}$ & $\begin{array}{l}(2.69-8.09) \\
(1.17-4.60) \\
(0.34-0.81)\end{array}$ & $\begin{array}{r}<0.001 \\
0.007 \\
0.002\end{array}$ \\
\hline $\begin{array}{l}\text { AD pathology score } \\
\text { Cerebral infarcts } \\
\text { Syntaxin/SNAP-25 interaction }{ }^{g}\end{array}$ & $\begin{array}{l}4.81 \\
2.01\end{array}$ & $\begin{array}{l}(2.82-8.22) \\
(1.04-3.88)\end{array}$ & $\begin{array}{c}<0.001 \\
0.02\end{array}$ & $\begin{array}{l}5.05 \\
1.97 \\
0.44\end{array}$ & $\begin{array}{l}(2.85-8.96) \\
(1.00-3.90) \\
(0.28-0.68)\end{array}$ & $\begin{aligned}< & 0.001 \\
& 0.02 \\
< & 0.001\end{aligned}$ \\
\hline
\end{tabular}

Abbreviations: AD, Alzheimer's disease; Cl, confidence interval; MAP, Memory and Aging Project; SNAP-25, synaptosomal-associated protein 25; VAMP, vesicleassociated membrane protein.

${ }^{a}$ Models are controlled for age, sex and education. ${ }^{b}$ Score as defined in the text. Range in sample $=0-3.1$ units. ${ }^{\mathrm{c}}$ Defined as present/absent. ${ }^{\mathrm{d}} Z$-score calculated as described in text. Range in sample $=-2.4$ to 2.2 units. ${ }^{e} Z$-score calculated as described in text. Range in sample $=-2.2$ to 2.2 units. ${ }^{f} Z$-score calculated as described in text. Range in sample $=-2.2$ to 2.7 units. ${ }^{9} Z$-score calculated as described in text. Range in sample $=-2.1$ to 2.6 units. 

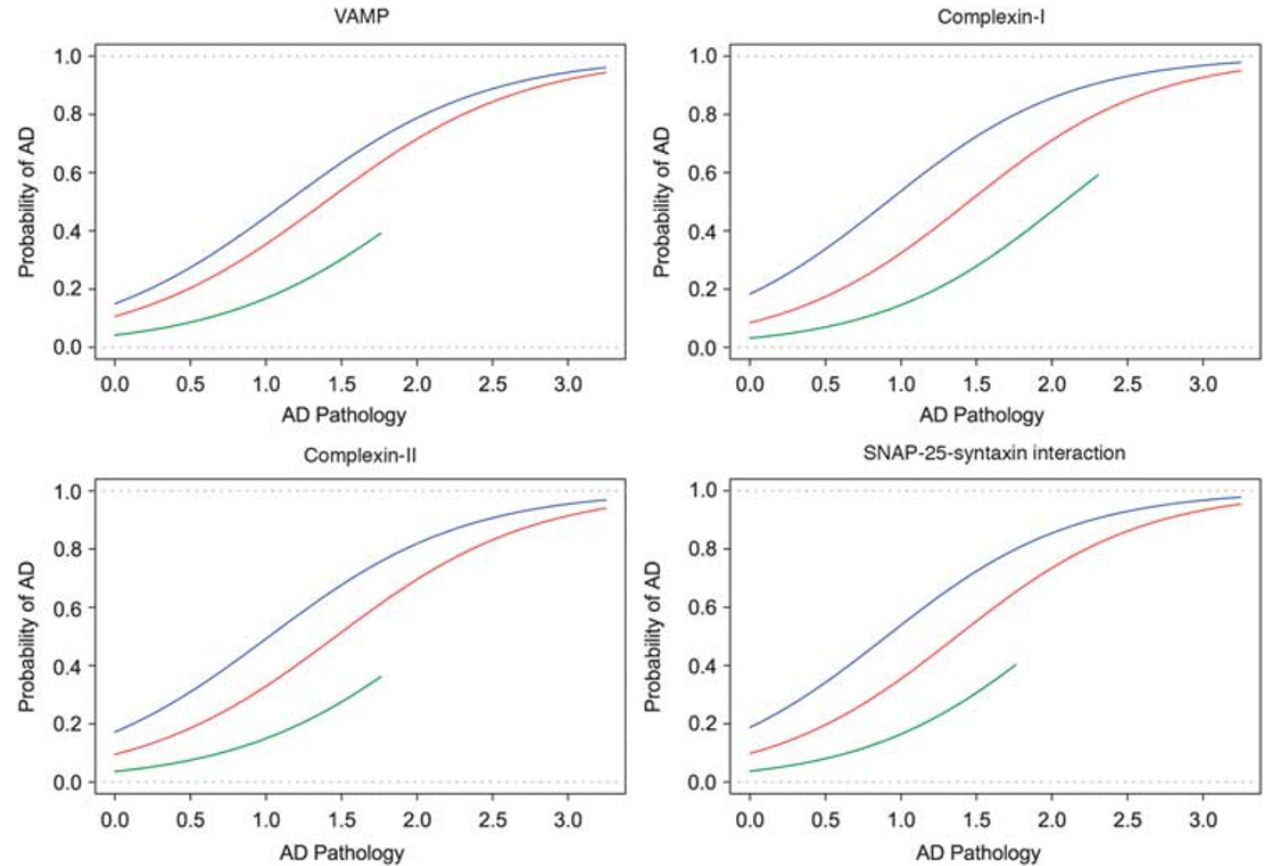

Figure 2 Probability of dementia illustrated for a female, age 88 years and with 14 years of education, representative of the sample. Percentiles of presynaptic proteins vesicle-associated membrane protein (VAMP), complexin-I, complexin-II and the synaptosomal-associated protein 25 (SNAP-25)/syntaxin interaction are shown as colored lines (green: 90th percentile, limited by the amount of available data, red: 50th percentile, blue: 10th percentile). Probability of dementia increases as Alzheimer's disease (AD) pathology increases, but may vary considerably depending on the levels of presynaptic proteins and protein-protein interactions.

Table 3 Linear regression model of associations of global cognitive function $z$-score with units of AD pathology, cerebral infarcts and units of presynaptic measures among $N=249$ deceased MAP participants ${ }^{\mathrm{a}}$

\begin{tabular}{|c|c|c|c|c|c|c|}
\hline & \multicolumn{3}{|c|}{ Global cognition } & \multicolumn{3}{|c|}{ Global cognition } \\
\hline & Model R2 & $\begin{array}{c}\text { Estimated } \beta \\
\text { coefficient }\end{array}$ & P-value & Model R2 & $\begin{array}{c}\text { Estimated } \beta \\
\text { coefficient }\end{array}$ & P-value \\
\hline $\begin{array}{l}\text { AD pathology score }{ }^{b} \\
\text { Cerebral infarcts } \\
\text { VAMP }^{\mathrm{c}}\end{array}$ & 0.28 & $\begin{array}{l}-0.73 \\
-0.32\end{array}$ & $\begin{array}{c}<0.001 \\
0.01\end{array}$ & 0.30 & $\begin{array}{r}-0.69 \\
-0.30 \\
0.17\end{array}$ & $\begin{array}{c}<0.001 \\
0.02 \\
0.03\end{array}$ \\
\hline $\begin{array}{l}\text { AD pathology score } \\
\text { Cerebral infarcts } \\
\text { Complexin- }^{\mathrm{e}}\end{array}$ & 0.28 & $\begin{array}{l}-0.73 \\
-0.32\end{array}$ & $\begin{array}{c}<0.001 \\
0.01\end{array}$ & 0.37 & $\begin{array}{r}-0.68 \\
-0.36 \\
0.43\end{array}$ & $\begin{array}{r}<0.001 \\
0.003 \\
<0.001\end{array}$ \\
\hline $\begin{array}{l}\text { AD pathology score } \\
\text { Cerebral infarcts } \\
\text { Complexin-II }\end{array}$ & 0.28 & $\begin{array}{l}-0.73 \\
-0.32\end{array}$ & $\begin{array}{c}<0.001 \\
0.01\end{array}$ & 0.32 & $\begin{array}{r}-0.69 \\
-0.37 \\
0.25\end{array}$ & $\begin{array}{r}<0.001 \\
0.004 \\
<0.001\end{array}$ \\
\hline $\begin{array}{l}\text { AD pathology score } \\
\text { Cerebral infarcts } \\
\text { Syntaxin/SNAP-25 interactiong }\end{array}$ & 0.28 & $\begin{array}{l}-0.73 \\
-0.32\end{array}$ & $\begin{array}{c}<0.001 \\
0.01\end{array}$ & 0.30 & $\begin{array}{r}-0.70 \\
-0.31 \\
0.20\end{array}$ & $\begin{array}{c}<0.001 \\
0.02 \\
0.007\end{array}$ \\
\hline
\end{tabular}

Abbreviations: AD, Alzheimer's disease; MAP, Memory and Aging Project; SNAP-25, synaptosomal-associated protein 25; VAMP, vesicle-associated membrane protein.

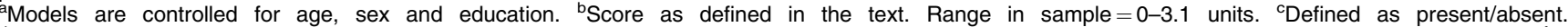
${ }^{\mathrm{d}} Z$-score calculated as described in text. Range in sample $=-2.4$ to 2.2 units. ${ }^{\mathrm{e}} Z$-score calculated as described in text. Range in sample $=-2.2$ to 2.2 units. ${ }^{\mathrm{f}} Z$ score calculated as described in text. Range in sample $=-2.2$ to 2.7 units. ${ }^{g} Z$-score calculated as described in text. Range in sample $=-2.1$ to 2.6 units.

pathology, presynaptic protein levels contribute to global cognitive function. An alternative presentation of this data (similar in format to Figure 2) appears as Supplementary Figure S1. Participants at higher percentiles for presynaptic markers had better cognitive function than those at lower percentiles, across multiple levels of $A D$ pathology. No statistical interactions between presynaptic markers and pathology were observed.
Cortical atrophy and presynaptic proteins. Cortical atrophy assessed semiquantitatively at post-mortem examination was not correlated with $A D$ pathology (Figure 4). However, correlations between cortical atrophy and levels of complexin-I (rho $=0.14, P=0.02$ ), and of complexin-II (rho $=0.17, P=0.008$ ) had small-to-medium effect sizes, as did the correlation with SNAP-25/syntaxin interaction (rho $=0.19, P=0.003$ ). Cortical atrophy was not 


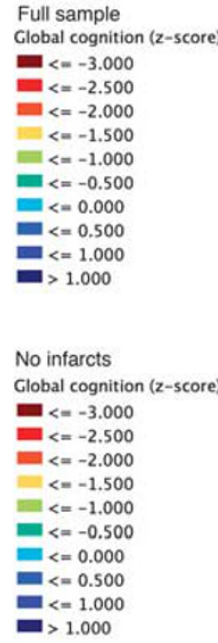
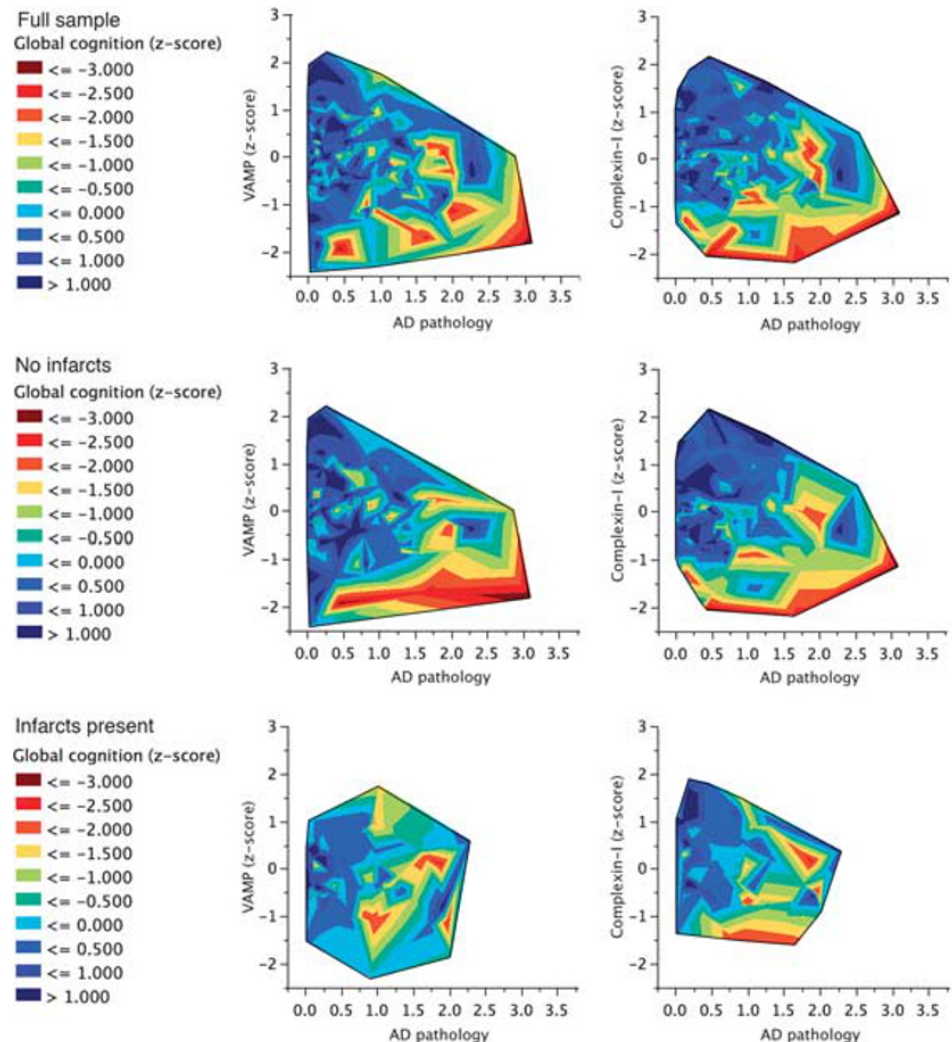
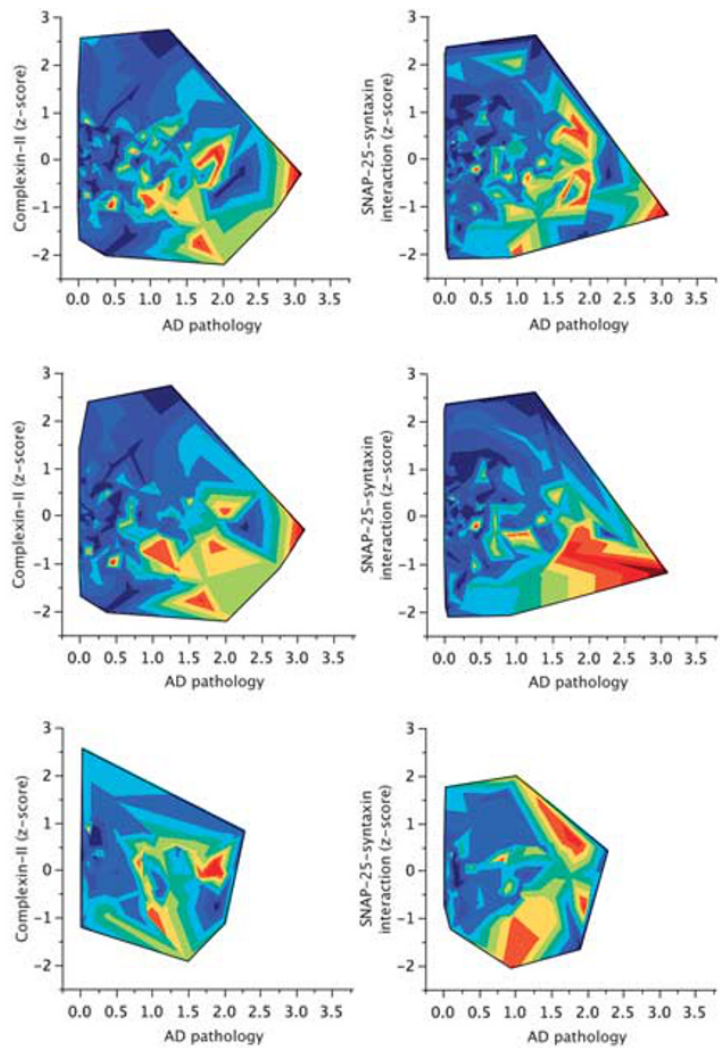

Figure 3 Global cognitive function (z-score, controlled for age, sex and education) illustrated for study participants in relation to levels of presynaptic proteins, proteinprotein interactions and severity of Alzheimer's disease (AD) pathology. For the full sample, as well as subsamples free of infarcts, or with infarcts present, both levels of presynaptic proteins and AD pathology contributed to global cognitive function. SNAP-25, synaptosomal-associated protein 25; VAMP, vesicle-associated membrane protein.

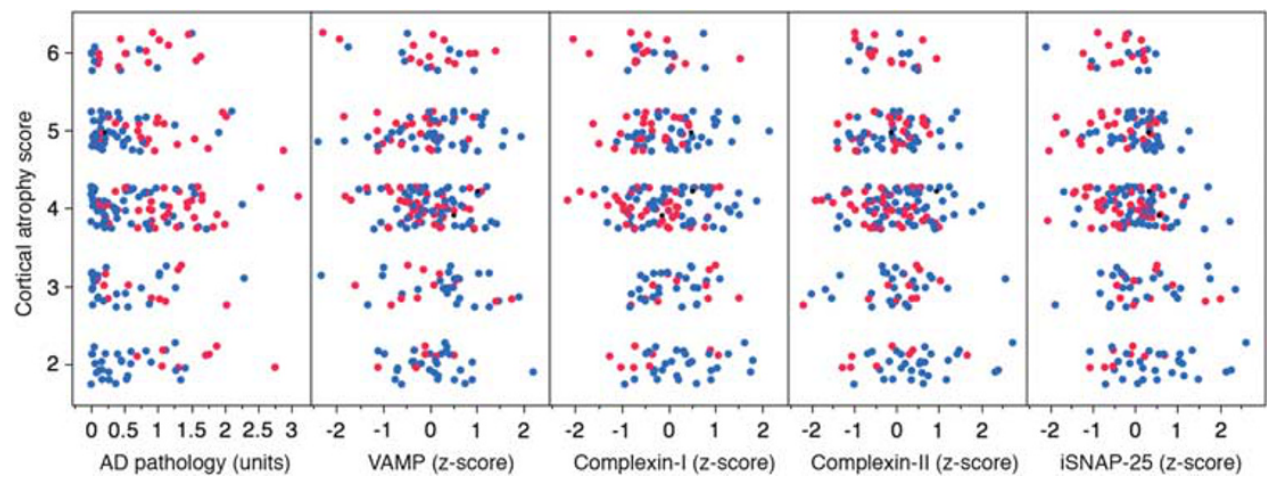

Figure 4 Relationships of cortical atrophy and pathological or synaptic variables. Cases of dementia are shown in red, and nondemented in blue. After controlling for age, sex and education, complexin-II levels and the synaptosomal-associated protein 25 (SNAP-25)/syntaxin interaction were associated with the extent of cortical atrophy. In contrast, Alzheimer's disease (AD) pathology did not predict cortical atrophy. VAMP, vesicle-associated membrane protein.

related to VAMP levels. When cortical atrophy was modeled as a function of age, sex, education and individual presynaptic proteins, the severity of cortical atrophy was associated with the level of complexin-II (estimate $=0.37$, $P=0.01)$ and of the SNAP-25/syntaxin interaction (estimate $=0.59, P<0.001$ ).

As this protein-protein interaction was quantified in homogenates, anatomical localization to specific terminal types was lost. To provide a neurochemical context, we used confocal microscopy to examine the relationship between the localization of the presynaptic proteins SNAP-25 and syntaxin, and markers of glutamatergic (excitatory) and GABAergic (inhibitory) terminals (Supplementary Figure S2). As expected, SNAP-25 and syntaxin immunoreactive pixels were highly colocalized (SNAP-25 overlap with syntaxin, 83\%; syntaxin overlap with SNAP-25, 74\%). SNAP-25-labeled pixels overlapped $64 \%$ with the vesicular glutamate transporter, but only $21 \%$ with the vesicular GABA transporter; similarly, syntaxin-containing pixels overlapped $43 \%$ with the vesicular glutamate transporter, 
but only $17 \%$ with the vesicular GABA transporter. These findings were consistent in the two cases examined, but only provide a context for interpretation of the SNARE interaction findings. More detailed and comprehensive studies would be needed to fully illuminate the neurochemical implications of the SNARE protein interaction results.

\section{Discussion}

In this community-based sample, both demented and nondemented individuals had a wide range of AD pathology, suggesting that additional factors contributed to the clinical status. Cerebral infarcts were present in $30 \%$, and increased the odds of dementia. Controlling for both $A D$ pathology and infarcts, higher levels of three specific presynaptic proteins (VAMP, complexin-I and complexin-II) were associated with better cognitive function and lower odds of dementia. A fourth measure represents a biological interaction between SNAP. 25 and syntaxin. Although the directly measured levels of these two proteins were not associated with cognitive function, the independent assay of their biological interaction was associated with cognition. These four presynaptic measures may represent structural or functional markers of cognitive reserve. Cortical atrophy was associated with complexin-II and the SNAP-25/syntaxin interaction, but not other synaptic or pathological measures.

Assaying multiple presynaptic proteins demonstrated some specificity for the associations of the synaptic vesicle protein VAMP, and complexins I and II with cognition in the elderly. Relatively selective loss of complexin proteins in $A D$ was noted previously in a small study, ${ }^{32}$ and other pathological and genetic evidence supports a role for these proteins in human cognitive function. ${ }^{33,34}$ Animal studies indicate that early-life experiences can alter complexin levels in adulthood, ${ }^{35}$ further supporting a model of presynaptic markers as molecular correlates of cognitive reserve.

The functionally important biological interaction between SNAP-25 and syntaxin was related to cognitive function, despite the absence of direct associations between the levels of these proteins and cognition. Greater biological interaction of SNAP-25 and syntaxin is associated with less glutamatergic neurotransmission in a transgenic mouse model. ${ }^{36}$ Less interaction, as seen here, could imply increased glutamate release with excitotoxicity, a process consistent with hyperactive neurons observed in an animal model of Alzheimer's disease. ${ }^{18}$ Interactions between SNAP-25 and syntaxin can be modulated by experimental drugs. ${ }^{37}$ This aspect of presynaptic integrity could represent a novel target for therapeutic interventions to forestall or alleviate cognitive impairment in the elderly.

We observed associations between autopsy-assessed cortical atrophy and levels of complexin-II and the SNAP-25/ syntaxin interaction. Although our assessment of cortical atrophy was a semiquantitative grading obtained postmortem, this finding establishes a foundation for future studies including magnetic resonance imaging of regional cortical thickness and surface area in life and post-mortem examination of pathology and synaptic measures. Synaptic markers of the structural component of cognitive reserve could contribute to the variation in magnetic resonance measures of gray matter before or in the early phases of cognitive dysfunction with aging.

Our cases exhibited the most common pathologies found in the elderly: $A D$ and infarcts. ${ }^{38,39}$ Cognitive function ranged from normal to moderately severe dementia. Specific presynaptic proteins may contribute to cognitive reserve particularly in the healthy elderly or in the early phases of cognitive decline. Once end-stage dementia occurs, our findings and those of others indicate that pan-synaptic loss occurs. Developing reliable assays of presynaptic proteins in cerebrospinal fluid could provide an interesting biomarker for future investigation of the cognitive reserve model, and of the possibility of early presynaptic pathology.

Although our sample was relatively large, few individuals were $<75$ years old. The findings may not generalize to those with cognitive impairment in the seventh decade of life or earlier. Finally, our measures were focused on the presynaptic compartment, and were from brain homogenates. Studies at an anatomical or cellular level of resolution and including postsynaptic markers might be more informative of mechanism.

In conclusion, multiple measures of synaptic proteins and interactions were associated with dementia, global cognitive function and cortical atrophy in a representative sample of people over 70 years of age. Consistent with a role in cognitive reserve, greater synaptic integrity appeared to protect the brain from manifesting cognitive impairment despite the accumulation of the two most common neuropathologies responsible for dementia. Presynaptic terminals are responsive to environmental manipulations and training. ${ }^{40}$ Presynaptic integrity could represent a novel target for therapeutic interventions designed to forestall or alleviate cognitive impairment in the elderly.

\section{Conflict of interest}

The authors declare no conflict of interest.

Acknowledgements. This study was supported by the BC Mental Health and Addictions Services, Canadian Institutes of Health Research (MOP-14037, CBG-101827), the Scottish Rite Charitable Foundation of Canada and the National Institute of Aging Grants R01AG17917 and R01AG31553. Dr. Honer reports receiving consulting fees or sitting on paid advisory boards for In-silico, Janssen, Roche and Novartis. We thank Donna Esbjornson for statistical programming; Hong-Ying Li, Jenny Yan and Ming Yang for performing laboratory assays; and the staff of the Rush Alzheimer's Disease Center and the participants in the Memory and Aging Project.

1. Stern Y. Cognitive reserve. Neuropsychologia 2009; 47: 2015-2028.

2. Selkoe DJ. Alzheimer's disease is a synaptic failure. Science 2002; 298: 789-791.

3. Washbourne P, Thompson PM, Carta M, Costa ET, Mathews JR, Lopez-Benditó G et al. Genetic ablation of the t-SNARE SNAP-25 distinguishes mechanisms of neuroexocytosis. Nat Neurosci 2002; 5: 19-26.

4. Glynn D, Bortnick RA, Morton AJ. Complexin II is essential for normal neurological function in mice. Hum Mol Genet 2003; 12: 2431-2448.

5. Drew CJ, Kyd RJ, Morton AJ. Complexin 1 knockout mice exhibit marked deficits in social behaviours but appear to be cognitively normal. Hum Mol Genet 2007; 16: 2288-2305.

6. Schoch S, Deak F, Konigstorfer A, Mozhayeva M, Sara Y, Südhof TC et al. SNARE function analyzed in synaptobrevin/VAMP knock-out mice. Science 2001; 294: 1117-1122. 
7. Fujiwara $\mathrm{T}$, Mishima $\mathrm{T}$, Kofuji $\mathrm{T}$, Chiba $\mathrm{T}$, Tanaka K, Yamamoto A et al. Analysis of knock-out mice to determine the role of HPC-1/syntaxin $1 \mathrm{~A}$ in expressing synaptic plasticity. J Neurosci 2006; 26: 5767-5776.

8. Schmitt U, Tanimoto N, Seeliger M, Schaeffel F, Leube RE. Detection of behavioral alterations and learning deficits in mice lacking synaptophysin. Neuroscience 2009; 162 234-243.

9. Webster MJ, Elashoff M, Weickert CS. Molecular evidence that cortical synaptic growth predominates during the first decade of life in humans. Int J Devel Neurosci 2011; 29: 225-236.

10. Troncoso JC, Zonderman AB, Resnick SM, Crain B, Pletnikova O, O'Brien RJ. Effect of infarcts on dementia in the Baltimore longitudinal study of aging. Ann Neurol 2008; 64 : 168-176.

11. Sonnen JA, Larson EB, Crane PK, Haneuse S, Li G, Schellenberg GD et al. Pathological correlates of dementia in a longitudinal, population-based sample of aging. Ann Neurol 2007; 62: 406-413.

12. Petrovitch H, Ross GW, Steinhorn SC, Abbott RD, Markesbery W, Davis D et al. AD lesions and infarcts in demented and non-demented Japanese-American men. Ann Neurol 2005 57: $98-103$

13. Terry RD, Masliah E, Salmon DP, Butters N, DeTeresa R, Hill R et al. Physical basis of cognitive alterations in Alzheimer's disease: synapse loss is the major correlate of cognitive impairment. Ann Neurol 1991; 30: 572-580.

14. Dickson DW, Crystal HA, Bevona C, Honer W, Vincent I, Davies P. Correlations of synaptic and pathological markers with cognition of the elderly. Neurobiol Aging 1995; 16: 285-304.

15. Scheff SW, Price DA, Schmitt FA, DeKosky ST, Mufson EJ. Synaptic alterations in CA1 in mild Alzheimer disease and mild cognitive impairment. Neurology 2007; 68: 1501-1508.

16. Minger SL, Honer WG, Esiri MM, McDonald B, Keene J, Nicoll JA et al. Synaptic pathology in prefrontal cortex is present only with severe dementia in Alzheimer's disease. $J$ Neuropathol Exp Neurol 2001; 60: 929-936.

17. Shankar GM, Li S, Mehta TH, Garcia-Munoz A, Shepardson NE, Smith I et al. Amyloid-beta protein dimers isolated directly from Alzheimer's brains impair synaptic plasticity and memory. Nat Med 2008; 14: 837-842.

18. Busche MA, Eichhoff G, Adelsberger $\mathrm{H}$, Abramowski D, Wiederhold KH, Haass $\mathrm{C}$ et al. Clusters of hyperactive neurons near amyloid plaques in a mouse model of Alzheimer's disease. Science 2008; 321: 1686-1689.

19. Petrie EC, Cross DJ, Galasko D, Schellenberg GD, Raskind MA, Peskind ER et al. Preclinical evidence of Alzheimer changes: convergent cerebrospinal fluid biomarke and fluorodeoxyglucose positron emission tomography findings. Arch Neurol 2009; 66: 632-637

20. Reiman EM, Caselli RJ, Yun LS, Chen K, Bandy D, Minoshima S et al. Preclinical evidence of Alzheimer's disease in persons homozygous for the epsilon 4 allele for apolipoprotein $\mathrm{E}$. New Engl J Med 1996; 334: 752-758.

21. Reiman EM, Chen K, Alexander GE, Caselli RJ, Bandy D, Osborne D et al. Functiona brain abnormalities in young adults at genetic risk for late-onset Alzheimer's dementia. Proc Natl Acad Sci USA 2004; 101: 284-289.

22. Barakauskas VE, Beasley CL, Barr AM, Ypsilanti AR, Li HY, Thornton AE et al. A nove mechanism and treatment target for presynaptic abnormalities in specific striatal regions in schizophrenia. Neuropsychopharmacology 2010; 35: 1226-1238.

23. Savva GM, Wharton SB, Ince PG, Forster G, Matthews FE, Brayne C. Age, neuropathology, and dementia. New Engl J Med 2009; 360: 2302-2309.

24. Bennett DA, Schneider JA, Buchman AS, de Leon CM, Bienias JL, Wilson RS. The Rush Memory and Aging Project: study design and baseline characteristics of the study cohort. Neuroepidemiology 2005; 25: 163-175.
25. Bennett DA, Schneider JA, Tang Y, Arnold SA, Wilson RS. The effect of social networks on the relation between Alzheimer's disease pathology and level of cognitive function in old people: a longitudinal cohort study. Lancet Neurol 2006; 5: 406-412.

26. Bennett DA, Schneider JA, Arvanitakis Z, Kelly JF, Aggarwal NT, Shah RC et al. Neuropathology of older persons without cognitive impairment from two community-based studies. Neurology 2006; 66: 1837-1844.

27. Schneider JA, Boyle PA, Arvanitakis Z, Bienias JL, Bennett DA. Subcortical infarcts, Alzheimer's disease pathology, and memory function in older persons. Ann Neurol 2007 62: $59-66$

28. Bennett DA, Wilson RS, Schneider JA, Evans DA, Aggarwal NT, Arnold SE et al. Apolipoprotein E epsilon4 allele, AD pathology, and the clinical expression of Alzheimer's disease. Neurology 2003; 60: 246-252.

29. Cohen J. A power primer. Psychol Bull 1992; 112: 155-159.

30. Levin JR. Overcoming feelings of powerlessness in "aging" researchers: a primer on statistical power in analysis of variance designs. Psychol Aging 1997; 12: 84-106.

31. Beasley CL, Honer WG, von Bergmann K, Falkai P, Lutjohann D, Bayer TA. Reductions in cholesterol and synaptic markers in association cortex in mood disorders. Bipolar Disord 2005; 7: 449-455.

32. Tannenberg RK, Scott HL, Tannenberg AE, Dodd PR. Selective loss of synaptic proteins in Alzheimer's disease: evidence for an increased severity with APOE varepsilon4. Neurochem Int 2006; 49: 631-639.

33. Sawada K, Barr AM, Nakamura M, Arima K, Young CE, Dwork AJ et al. Hippocampal complexin proteins and cognitive dysfunction in schizophrenia. Arch Gen Psychiatry 2005 62: $263-272$

34. Begemann M, Grube S, Papiol S, Malzahn D, Krampe H, Ribbe K et al. Modification of cognitive performance in schizophrenia by complexin 2 gene polymorphisms. Arch Gen Psychiatry 2010; 67: 879-888.

35. Barr AM, Hofmann CE, Phillips AG, Weinberg J, Honer WG. Prenatal ethanol exposure in rats decreases levels of complexin proteins in the frontal cortex. Alcohol Clin Exp Res 2005; 29: 1915-1920.

36. Jeans AF, Oliver PL, Johnson R, Capogna M, Vikman J, Molnár Z et al. A dominant mutation in Snap25 causes impaired vesicle trafficking, sensorimotor gating, and ataxia in the blind-drunk mouse. Proc Natl Acad Sci USA 2007; 104: 2431-2436.

37. Yang $Y$, Shin JY, Oh JM, Jung $\mathrm{CH}$, Hwang Y, Kim S et al. Dissection of SNARE-driven membrane fusion and neuroexocytosis by wedging small hydrophobic molecules into the SNARE zipper. Proc Natl Acad Sci USA 2010; 107: 22145-22150.

38. Schneider JA, Arvanitakis Z, Bnag W, Bennett DA. Mixed brain pathologies account for most dementia cases in community-dwelling older persons. Neurology 2007 6: 2197-2204.

39. Smith MZ, Nagy Z, Barnetson L, King EM-F, Esiri MM. Coexisting pathologies in the brain: influence of vascular disease and Parkinson's disease on Alzheimer's pathology in the hippocampus. Acta Neuropathol 2000; 100: 87-94.

40. Cracchiolo JR, Mori T, Nazian SJ, Tan J, Potter H, Arendash GW. Enhanced cognitive activity-over and above social or physical activity-is required to protect Alzheimer's mice against cognitive impairment, reduce Abeta deposition, and increase synaptic immunoreactivity. Neurobiol Learn Mem 2007; 88: 277-294.

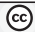

Translational Psychiatry is an open-access journal published by Nature Publishing Group. This work is licensed under the Creative Commons Attribution-Noncommercial-No Derivative Works 3.0 Unported License. To view a copy of this license, visit http://creativecommons.org/licenses/by-nc-nd/3.0/

\section{Supplementary Information accompanies the paper on the Translational Psychiatry website (http://www.nature.com/tp)}

